\title{
Fentanyl-Propofol versus Dexmedetomidine for procedural sedation during gastrointestinal endoscopies in children
}

\author{
Dario Galante', Flavio Badii', Ettore Melai3, Dino Pedrotti ${ }^{4}$, \\ Massimo Savino Lambo5, Livia Cococcia ${ }^{6}$
}

1 University Department of Anesthesia and Intensive Care, University Hospital Ospedali Riuniti of Foggia, Italy

2Department of Anesthesia and Intensive Care, Hospital of Vittorio Veneto, Italy

${ }^{3}$ Department of Anesthesia and Intensive Care, Ospedale Unico della Versilia, Lido di Camaiore, Italy

${ }^{4}$ Department of Anesthesia and Intensive Care, S. Chiara Hospital, Trento, Italy

${ }^{5}$ Department of Anesthesia and Intensive Care, Spirito Santo Hospital, Pescara, Italy

${ }^{6}$ Department of Anesthesia and Intensive Care, SS Annunziata Hospital, Sulmona, Italy

\section{Background and Goal of Study}

The objective of our research is to evaluate pediatric patient anxiety and discomfort during gastrointestinal $(\mathrm{Gl})$ endoscopies comparing the clinical efficacy and safety of Fentanyl + Propofol (FentP) and Dexmedetomidine + Propofol (DexP) when procedural sedation in pediatric patients is performed (1).

Materials and Methods

A systematic multicentric review of our recorded data was analyzed. ASA I-II children, aged between 4 to 14 years were enrolled to 2 groups: Dexmedetomidine and Propofol (DexP) or Fentanyl and Propofol (FentP) groups. The DexP group received Dexmedetomidine $1 \mu \mathrm{g} / \mathrm{kg}$ over 10 minutes and Propofol $(50 \mu \mathrm{g} / \mathrm{kg} / \mathrm{min})$; the FentP group received IV bolus Fentanyl $1 \mu \mathrm{g} / \mathrm{kg}$ followed by Propofol $(50 \mu \mathrm{g} / \mathrm{kg} / \mathrm{min})$ for maintenance. Propofol rescue doses $0.5-1 \mathrm{mg} / \mathrm{kg}$ were administered if patients showed discomfort in both groups.

Results and Discussion

Both groups were homogeneous in ASA class, age, demographics, cardiorespiratory and hemodynamic parameters. The mean heart rate, systolic and diastolic noninvasive arterial pressure during surgical and anesthesia procedures were lower in the DexP group as compared to FentP group and difference was statically significant $(\mathrm{P}<0.05)$. Respiratory rate and $\mathrm{SpO}_{2}$ were lower in FentP group. Sedation scores, evaluated with Ramsay scale, were observed in DexP group. The mean recovery time (DexP vs FentP, 8.7 vs 10.56 mins) and length of stay in recovery (DexP vs FentP, 12.9 vs 15.14 mins) was lesser in DP group and the difference was statically significant $(P<$ 0.05). The average number of rescue doses of Propofol used during the procedure were significantly less in DexP group as compared to the FentP group (DexP vs FentP, $1.84 \pm 0.76$ vs $3.72 \pm 1.16, P$ Value $<0.0001$ ) (Figure1).

The efficacy of analgesia in patients of both groups was assessed by Wong Baker Faces Pain Rating Scale and was comparable.

\section{Conclusions}

Dexmedetomidine in association with Propofol, according to our study and experience, is considered preferable because it is associated with shorter recovery time, efficacy of analgesia, without complications and adverse effects on hemodynamic and respiratory parameters and may be considered a valid alternative for procedural sedation in pediatric patients undergoing gastrointestinal endoscopies.

\section{References}

1. Parker MM. Dexmedetomidine: Is It the Answer to All of Our Sedation Challenges?_Pediatr Crit Care Med. 2016;17:1183-1184.
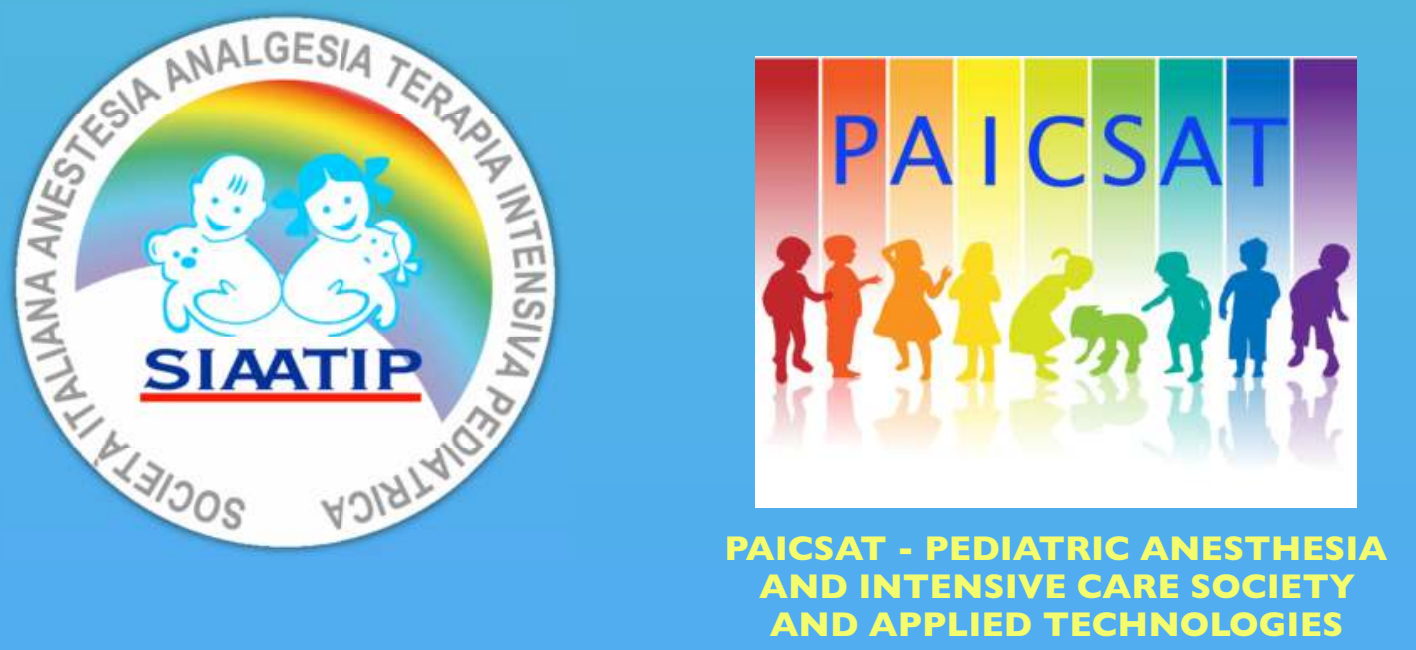

Geneva, Switzerland Euroanaesthesia 17

3- 5 June

Copyright (C) 2017 Dario Galante ${ }^{1}$, Flavio Badii ${ }^{2}$, Ettore Melai ${ }^{3}$, Dino Pedrotti ${ }^{4}$, Massimo Savino Lambo ${ }^{5}$ Livia Cococcia $^{6}$ 